cent increase in respiration. Sucrose was not hydrolysed prior to accumulation, and when slices accumulated sugar from a mixed solution, sucrose uptake inhibited glucose uptake. Internodes which were most active in storing sugar in the field gave the most actively accumulating preparations in laboratory experiments. Mature tissue slices showed little or no ability to accumulate sugars.

In further work on the effects of inhibitors on sugar accumulation, the author (ibid., p. 221) has noted that various metabolic inhibitors, at $p \mathbf{H} \tilde{5} \cdot \mathbf{5}$, affect sugar accumulation in immature sugar-cane storage tissues. The rate of accumulation was reduced by $10^{-5} M$ mercuric ion, $10^{-5} M p$-chloromercuribenzoate, cyanide, and cupric ion, and $2 \times$ $10^{-8} M$ phloridzin. Accumulation was completely inhibited and sugar leakage induced by $10^{-5} M$ dinitrophenol, $10^{-4} M$ mercuric ion, and $10^{-3} M$ $p$-chloromercuribenzoate, cvanide, cupric ion, azide, arsenate, and iodoacetate. The effects of $10^{-5} M$ dinitrophenol and $10^{-4} M$ cyanide were reversible, but that of $10^{-3} M$ cyanide was irreversible. Only slight effects were produced by borate, phosphate and magnesium ions. The behaviour of sugar-cane sugar accumulation towards inhibitors is apparently similar to that of other transport mechanisms, being somewhat more sensitive than most plant processes and less so than animal ones. It differed from sugar accumulation in animal tissues in showing no specific sensitivity to phloridzin. The results suggest that sugars are contained within the immature storage cell by the continuous operation of a metabolic storage mechanism rather than by an impenetrable barrier to sugar diffusion.

\title{
VIRUSES AND PLANT DISEASES
}

\begin{abstract}
$\mathrm{T}$ HE investigations of Dr. L. O. Kunkel into the relationships between viruses and plant diseases are described in the Rockefeller Institute Quarterly (4, No. 2 ; Summer, 1960).

Kunkel discovered that the aster yellows disease is carried by a leafhopper and is caused by one of the few viruses that is equally at home in hosts of the plant and animal worlds. First, he observed that during the hot summer months the aster yellows disease diminishes in plants, and showed that the causative virus is sensitive to heat. Dr. Kunkel was able to cure infected plants of several virus diseases by growing them at temperatures which destroyed the virus without destroying the plants. Peach yellows is one of the diseases which responded to heat treatment. The heat-treatment technique also enabled Dr. Kunkel to deduce that the aster yellows virus multiplies in its leafhopper carrier as well as in the plant it infects. To do this, he subjected the insects to heat and noted how they regained their infectivity. $\mathrm{He}$ concluded that the virus must multiply in the insects, reaching a level of maximum infectivity in about two weeks. Direct evidence for this was found by L. M. Black, using a technique developed in Africa by the English scientist, $H$. $H$. Storey, to inoculate minute leafhoppers with measured amounts of virus.

Secondly, in his work on the transmission of yellows viruses, Dr. Kunkel discovered two related strains of aster yellows virus, each of which will protect plants against infection by the other, a phenomenon known
\end{abstract}

as cross-protection. He also found cross-protection between viruses in the leafhoppers as well. Dr. Karl Maramorosch, who began work at the Institute with Dr. Kunkel, has continued his studies of plant viruses. $\mathrm{He}$ confirmed the complex relationships existing between two strains of the corn stunt virus and the leafhopper that transmits them from plant to plant. Of the two strains of the virus, plants infected by one are protected against infection by the other, but the second will not protect a plant against the first. Similarly, infection of a leafhopper by the first will prevent it from becoming infected afterwards with and transmitting the second. In the insect also, the second virus strain will not protect against the first. These findings regarding corn stunt virus confirmed Kunkel's discovery that two related strains of aster yellows virus would protect leafhoppers against each other, but Dr. Maramorosch was the first to find unilateral protection.

Maramorosch has also found that a leafhopper which normally feeds on corn can live on aster plants only if the aster's are infected with the aster yellows virus. After they feed on diseased asters, the corn leafhoppers are then able to survive on uninfected aster plants. They are then also able to survive on healthy carrot plants, which they could not do before their diet of diseased aster plants. It would appeax that the virus infection may actually benefit the insect by widening its potential food plants. The explanation of these phenomena is not yet clear, but Dr. Maramorosch is pursuing his investigations.

\section{DISTILLATION OF ALKALI ELEMENTS DURING FORMATION OF AUSTRALITE FLANGES}

\author{
By DR. S. R. TAYLOR* \\ Department of Geochemistry, University of Cape Town
}

THE flanged australites (Figs. 1 and 2 ) are the
most distinctive members of this well-preserved
group of tektites. The common australite forms are
distinguished by Fenner ${ }^{1}$ as round (buttons and
* Canberra. lenses), oval (ovals, boats and canoes), dumbbells and teardrops. 'Cores' may be round, oval or dumbbell shapes. The flanges, which occur most commonly on the round forms, but occasionally on the other types as well, display the often quoted evidence for two periods of melting of tektites. Sections 